Original

\title{
Site-specificity of pain sensitivity to intraoral anesthetic injections in children
}

\author{
Naser A. Aminabadi, Ramin M. Z. Farahani and Sina G. Oskouei \\ Department of Pedodontics, School of Dentistry, Tabriz University (Medical Sciences), Tabriz, Iran
}

(Received 1 May 2008 and accepted 14 March 2009)

\begin{abstract}
A total of 455 children (242 males and 213 females) aged 5-6 years were investigated for their pain reactions to maxillary and mandibular infiltration anesthesia, middle superior alveolar nerve block, posterior superior alveolar nerve block, greater palatine nerve block, nasopalatine nerve block, and inferior alveolar nerve block, and the responses were quantified using the sound, eye and motor (SEM) scale. Administration of nasopalatine nerve block produced maximum pain (median SEM score: 10) while that of posterior superior alveolar nerve block and inferior alveolar nerve block was accompanied by minimum pain ( 3 and 4 , respectively). There was no significant gender-specific difference in pain reactions $(P=0.39)$. Administration of local anesthesia in the maxilla was more painful than injections into the mandible ( 7 versus $5, P<0.05)$. Furthermore, infiltration into the anterior and posterior segments of the maxilla produced maximum and minimum pain reactions, respectively (8 versus $3, P<0.001)$. It seems that the anatomical location of an injection is one of the most important determinants of pediatric pain reaction, and that mandibular injections are generally less painful. Prioritization of treatment by consideration of sitedependent variability in pain sensitivity may help to achieve optimal behavioral control during dental treatment in young children. (J Oral Sci 51, 239-243, 2009)
\end{abstract}

Correspondence to Dr. Naser Asl Aminabadi, School of Dentistry, Tabriz University (Medical Sciences), Golgasht St, Daneshgah St, Tabriz, Iran

Tel: +98-411-3440310

Fax: +98-411-3346977

E-mail: aslaminabadi@gmail.com
Keywords: pain; local anesthesia; age; gender; anatomical location.

\section{Introduction}

It is generally accepted that one of the most important aspects of pediatric behavior management in dental practice is pain control (1). Intraoral anesthesia is commonly used for children as well as adults in conventional dentistry but, paradoxically, administration of local anesthetic itself produces pain and anxiety that may cause subsequent unfavorable behavior (2).

A number of methods have been suggested to reduce the pain induced by infiltration of local anesthetic agents. These include application of topical analgesics such as amethocaine (3), suggestion (4), distraction techniques (5), counterirritation (6), warming the anesthetic agents (7), varying the rates of infiltration (8), buffering the local anesthesia, and a reduced speed of injection (9-14). However, the efficiency of these complementary methods in reducing the pain reaction is a matter of debate, and the site-specific pain reaction to an anesthetic injection has not been studied so far.

The aim of the present study was to evaluate the pediatric reaction to the pain produced by various injection techniques in different intraoral regions of the upper and lower jaws.

\section{Study population}

Materials and Methods

A total of 455 children (male: 242, female: 213 ) aged $5-6$ years (mean age: 5.4 years) were included in the present clinical trial. The subjects presented at the Department of Pedodontics, Tabriz University of Medical Sciences, School of Dentistry, for the treatment of carious 
primary teeth. The selected subjects were in complete physical and mental health without any confounding medical history.

The following criteria were considered for inclusion into the study:

- Existence of carious primary molars necessitating administration of an anesthetic agent.

- No history of post-traumatic stress disorder or specific phobia related to dental settings.

- No history of unpleasant experiences in medical settings.

- No previous experience of intraoral injections.

- No history of pain secondary to pulpitis favoring a biased context due to special pain status such as hyperalgesia or allodynia.

- No allergic reaction to lidocaine.

The study procedure as well as probable risks and discomforts were explained to the parents/guardians of the patients. They were also informed of the less common techniques used as part of the present study for local anesthesia which entailed greater palatine and nasopalatine nerve blocks instead of mesial and distal local infiltration anesthesia. The study design was approved by the Ethics Committee and Research Council of Tabriz University of Medical Sciences. The children were enrolled in the trial after receipt of a signed consent form from their parents/ guardians.

\section{Selection of subjects}

During the first therapeutic session, fluoride therapy was performed for the subjects, and only cooperative children (rating of 3 or 4 on the Frankl scale) were included in the study. The Frankl scale (15) divides observed behavior into four categories, ranging from definitely positive to definitely negative, as follows:

Rating 1: Definitely negative, refusal of treatment, forceful crying, fearfulness, or any other overt evidence of extreme negativism.

Rating 2: Negative, reluctance to accept treatment, uncooperativeness, some evidence of negative attitude but not pronounced (sullen, withdrawn).

Rating 3: Positive, acceptance of treatment; cautious behavior at times; willingness to comply with the dentist, at times with reservation, but patient follows the dentist's directions cooperatively.

Rating 4: Definitely positive, good rapport with the dentist, interest in the dental procedures, laughter and enjoyment.

\section{Management during intraoral injection}

All injections were performed by a single pediatric dentist. Topical anesthesia was achieved with $20 \%$ benzocaine gel (Xylonor gel; Septodont Inc., Newcastle, Delaware, USA) applied over the dried mucosa for 1 minute using a cotton applicator. Prior to injection, all needles and anesthetic solutions (Lidocaine 2\%, Epinephrine 1/100,000, Astra Pharmaceuticals Ltd., Kings Langley, UK) were placed in a warmer that kept the solution temperature at $40^{\circ} \mathrm{C}$. The anesthetic solution was applied through 27 -gauge ( $32 \mathrm{~mm}$ in length) needles for one minute. Distraction and counterstimulation methods were used during the injections. Counterstimulation involved the use of the thumb to create vibration with slight pressure on the soft tissue adjacent to the injection site (16). The range of vibration movement was approximately $1 \mathrm{~mm}$ (short back and forth / up and down movements) and the frequency of vibration was 1 cycle/s. The distraction technique involved asking the subject to raise the right and left legs in turn using the voice control technique.

\section{Assessment of children's behavior}

A second dentist assessed the children's pain reaction during injections according to the sound, eye and motor (SEM) scale (17). The assessment criteria of the SEM scale are presented in Table 1. The experimenter, standing at a distance of $1.5 \mathrm{~m}$ from the dental chair, evaluated the children's sounds, eye signs, and body movements during injection. The SEM score was calculated by summing the three "Grade" values. On a random basis, a third experimenter performed the SEM evaluation along with the second experimenter in order to evaluate the inter-examiner reliability of the SEM data.

\section{Statistical analysis}

SEM scores are presented as the median. Statistical analysis of data was performed using the non-parametric Kruskal-Wallis test. Subsequently, Mann-Whitney $U$-test was used to detect individual between-group differences. Intra-examiner agreement of data was evaluated using Kappa statistics. Differences at $P<0.05$ were considered statistically significant.

\section{Results}

No adverse event was observed during the study course. The inter-examiner agreement of data for the SEM score was 0.88 and the intra-examiner agreement for the SEM was 0.89 .

\section{Univariate analysis of SEM scores}

Table 2 shows the median SEM scores for the intraoral anesthetic injections. The nasopalatine nerve block 
Table 1 SEM scale for the assessment of children's behavior

\begin{tabular}{lclll}
\hline Parameter & \multicolumn{1}{c}{ Comfort } & \multicolumn{1}{c}{ Mild discomfort } & Moderate discomfort & \multicolumn{1}{c}{ Severe discomfort } \\
\hline Grade & 1 & 2 & 3 & 4 \\
Sound & no sound & $\begin{array}{l}\text { non-specific sound } \\
\text { (probable pain) }\end{array}$ & $\begin{array}{l}\text { verbal complaint, } \\
\text { louder sound }\end{array}$ & $\begin{array}{l}\text { verbal complaint shouting, } \\
\text { crying }\end{array}$ \\
Eye & no sign & $\begin{array}{l}\text { dilated eye without tear } \\
\text { (anxiety sign) }\end{array}$ & $\begin{array}{l}\text { tears, sudden eye } \\
\text { movements }\end{array}$ & crying, tears all over the face \\
Motor & $\begin{array}{l}\text { muscular contraction, } \\
\text { relaxed body and } \\
\text { hand status }\end{array}$ & $\begin{array}{l}\text { sudden body and hand } \\
\text { movements }\end{array}$ & $\begin{array}{l}\text { hand movements for } \\
\text { defense, turning the head to } \\
\text { the opposite side }\end{array}$ \\
\hline
\end{tabular}

Table 2 Median SEM score for the intraoral injection techniques

\begin{tabular}{ll}
\hline Technique & Median SEM score \\
\hline Inferior alveolar nerve block $(n=75)$ & 6 \\
Mandibular anterior local infiltration $(n=43)$ & 5 \\
Mandibular posterior local infiltration $(n=53)$ & 6 \\
Middle superior alveolar nerve block $(n=68)$ & 3 \\
Posterior superior alveolar nerve block $(n=89)$ & 8 \\
Maxillary anterior local infiltration $(n=79)$ & 8 \\
Greater palatine nerve block $(n=25)$ & 10 \\
Nasopalatine nerve block $(n=23)$ & \\
\hline
\end{tabular}

produced a maximum pain reaction (median SEM score, 10) and the posterior superior alveolar nerve block and inferior alveolar nerve block were least painful ( 3 and 4 , respectively). The SEM scores for maxillary injections well exceeded those for mandibular injections ( 7 for maxilla $[\mathrm{n}=284]$ versus 5 for mandible $[n=171])$.

\section{Between-group analysis of SEM scores}

The effect of sex on pain perception was not significant $(P>0.05)$. The median SEM scores for male $(n=213)$ and female $(n=242)$ subjects were both 4 . In both genders, comparison of SEM values for the maxilla and mandible revealed a significant difference $(P<0.05)$, with higher scores for the maxilla. Based on the results of the MannWhitney $U$-test, injection techniques were categorized into four main groups, for which there were no statistically significant differences in SEM scores between the members of each group (Table 3): low SEM score (posterior superior alveolar nerve block and inferior alveolar nerve block), moderate SEM score (middle superior alveolar nerve block, mandibular anterior local infiltration and mandibular posterior local infiltration), high SEM score (maxillary anterior local infiltration and greater palatine nerve block), and maximum SEM score (nasopalatine injection).

\section{Discussion}

The aim of the present study was to evaluate the pediatric pain reaction to various injection techniques in different intraoral regions. In the present study, we evaluated eight common intraoral injection techniques in children, including: maxillary local infiltration, middle superior alveolar nerve block, posterior superior alveolar nerve block, greater palatine nerve block, nasopalatine nerve block, inferior alveolar nerve block, and mandibular anterior and posterior local infiltration. The SEM scale used in our study has been proved to be a reasonable and valid 
Table 3 Group to group comparison of injection techniques

\begin{tabular}{|c|c|c|c|c|c|c|c|c|}
\hline $\begin{array}{l}\text { Results of } \\
\text { post-hoc test }\end{array}$ & $\begin{array}{l}\text { Inferior } \\
\text { alveolar } \\
\text { nerve } \\
\text { block }\end{array}$ & $\begin{array}{l}\text { Mandibular } \\
\text { anterior local } \\
\text { infiltration }\end{array}$ & $\begin{array}{l}\text { Mandibular } \\
\text { posterior local } \\
\text { infiltration }\end{array}$ & $\begin{array}{l}\text { Middle } \\
\text { superior } \\
\text { alveolar } \\
\text { nerve } \\
\text { block }\end{array}$ & $\begin{array}{l}\text { Posterior } \\
\text { superior } \\
\text { alveolar } \\
\text { nerve block }\end{array}$ & $\begin{array}{l}\text { Maxillary } \\
\text { anterior local } \\
\text { infiltration }\end{array}$ & $\begin{array}{l}\text { Greater } \\
\text { palatine } \\
\text { nerve } \\
\text { block }\end{array}$ & $\begin{array}{l}\text { Nasopalatine } \\
\text { nerve block }\end{array}$ \\
\hline $\begin{array}{l}\text { Inferior alveolar } \\
\text { nerve block }\end{array}$ & - & $*$ & $*$ & $*$ & NS & $*$ & $*$ & $*$ \\
\hline $\begin{array}{l}\text { Mandibular } \\
\text { anterior local } \\
\text { infiltration }\end{array}$ & $*$ & - & NS & NS & $*$ & $*$ & * & $*$ \\
\hline $\begin{array}{l}\text { Mandibular } \\
\text { posterior local } \\
\text { infiltration }\end{array}$ & $*$ & NS & - & NS & $*$ & $*$ & $*$ & $*$ \\
\hline $\begin{array}{l}\text { Middle superior } \\
\text { alveolar nerve } \\
\text { block }\end{array}$ & $*$ & NS & NS & - & $*$ & $*$ & $*$ & $*$ \\
\hline $\begin{array}{l}\text { Posterior } \\
\text { superior alveolar } \\
\text { nerve block }\end{array}$ & NS & $*$ & $*$ & * & - & * & $*$ & $*$ \\
\hline $\begin{array}{l}\text { Maxillary } \\
\text { anterior local } \\
\text { infiltration }\end{array}$ & $*$ & $*$ & $*$ & $*$ & * & - & NS & $*$ \\
\hline $\begin{array}{l}\text { Greater palatine } \\
\text { nerve block }\end{array}$ & $*$ & * & $*$ & $*$ & $*$ & NS & - & $*$ \\
\hline $\begin{array}{l}\text { Nasopalatine } \\
\text { nerve block }\end{array}$ & * & $*$ & $*$ & $*$ & $*$ & * & * & - \\
\hline
\end{tabular}

scale for measuring the degree of comfort or pain in children (17). We found that the posterior segment of the maxilla exhibited minimum pain scores, followed in ascending order by the posterior segment of mandible, the anterior segment of the mandible and the anterior segment of the maxilla. Our findings also revealed that maxillary injections of the anesthetic agent produced a higher level of pain compared to mandibular injections, and the difference between maxilla and mandible was statistically significant in both the anterior and the posterior regions. Further evidence supporting our findings comes from the studies of Ram and Peretz $(18,19)$, which showed that more children reacted positively during the administration of mandibular nerve block than during maxillary infiltration. Our data also suggest that nasopalatine nerve block, anterior local infiltration and greater palatine nerve block produce significantly more severe pain than injections into the other sites. Probably, the firmly attached tissue in the palatal and anterior regions of the maxilla and the pressure created by injections are responsible for these outcomes (20).

Our study showed that gender does not play a role in children's reaction to pain, which is in accordance with findings of Ram and Peretz (18,19), and Allin et al. (21), who reported no significant gender-specific difference in children's reactions to intraoral injection. In contrast, Peretz and Efrat (22) suggested gender-specific differences with respect to dental anxiety in general and fear of the needle. Pain scores were significantly higher in girls than in boys (22). This disagreement between their findings and ours may be due to the fact that in the aforementioned study, data were obtained from a self-report completed by the patients in the waiting room before the dental treatment sessions, and this would have been influenced by previous dental experiences. In our study, the SEM scale was used for measuring the reactions of children who had no previous experience of injection, and the children had good rapport with the practitioner. Therefore, it is plausible that the behavioral management we employed during intraoral injection in this study minimized any influence of dental anxiety on the pain scores.

In our study, inferior alveolar nerve block was accompanied by a less severe pain reaction than mandibular infiltration. However, this finding was not in agreement with the results of a study conducted by Sharaf (23). The difference may partly reflect our study design with regard to the application of complementary methods of distraction and counterstimulation. It has been shown that distraction and counterstimulation effectively reduce the pain reaction of pediatric patients during anesthetic injection (16).

It is concluded that the anatomical location of intraoral injection is one the most important determinants of the resulting pain reaction. With reference to a prioritized treatment plan, it is suggested that the operator begins with 
infiltration in the posterior segment of the maxilla, proceeding through the mandible to the anterior segment of the maxilla, which should be the last site considered for injection. In addition, it can be implied that if the same procedures are followed during an injection, then the anatomical site rather than the injection technique determines the severity of the pain reaction. This pattern is in accordance with Pinkham's recommendation for the sequence of operative treatments in various intraoral regions (24).

\section{References}

1. Nuttall NM, Bradnock G, White D, Morris J, Nunn J (2001) Dental attendance in 1998 and implications for the future. Br Dent J 190, 177-182.

2. Fiset L, Milgrom P, Weinstein P, Getz T, Glassman P (1985) Psychophysiological responses to dental injections. J Am Dent Assoc 111, 578-583.

3. O'Brien L, Taddio A, Lyszkiewicz DA, Koren G (2005) A critical review of the topical local anesthetic amethocaine (Ametop) for pediatric pain. Paediatr Drugs 7, 41-54.

4. Pollack S (1966) Pain control by suggestion. J Oral Med 21, 89-95.

5. Touyz LZ, Lamontagne P, Smith BE (2004) Pain and anxiety reduction using a manual stimulation distraction device when administering local analgesia oro-dental injections: a multi-center clinical investigation. J Clin Den 15, 88-92.

6. Ong EL, Lim NL, Koay CK (2000) Towards a painfree venopuncture. Anaesthesia 55, 260-262.

7. Colaric KB, Overton DT, Moore K (1998) Pain reduction in lidocaine administration through buffering and warming. Am J Emerg Med 16, 353356.

8. Scarfone RJ, Jasani M, Gracely EJ (1998) Pain of local anesthetics: rate of administration and buffering. Ann Emerg Med 31, 36-40.

9. Bartfield JM, Crisafulli KM, Raccio-Robak N, Salluzzo RF (1995) The effects of warming and buffering on pain of infiltration of lidocaine. Acad Emerg Med 2, 254-258.

10. Courtney DJ, Agrawal S, Revington PJ (1999) Local anaesthesia: to warm or alter the $\mathrm{pH}$ ? A survey of current practice. J R Coll Surg Edinb 44, 167-171.

11. Younis I, Bhutiani RP (2004) Taking the 'ouch' out - effect of buffering commercial xylocaine on infiltration and procedure pain - a prospective, randomised, double-blind, controlled trial. Ann R
Coll Surg Engl 86, 213-217.

12. Orlinsky M, Hudson C, Chan L, Deslauriers R (1992) Pain comparison of unbuffered versus buffered lidocaine in local wound infiltration. $\mathrm{J}$ Emerg Med 10, 411-415.

13. Masters JE (1998) Randomised control trial of $\mathrm{pH}$ buffered lignocaine with adrenaline in outpatient operations. Br J Plast Surg 51, 385-387.

14. Fitton AR, Ragbir M, Milling MA (1996) The use of $\mathrm{pH}$ adjusted lignocaine in controlling operative pain in the day surgery unit: a prospective, randomised trial. Br J Plast Surg 49, 404-408.

15. Wright GZ (2004) Nonpharmacologic management of children's behaviors. In: Dentistry for the child and adolescent. McDonald RE, Avery DR, Dean JA eds, 8th ed, St Louis, Mosby, 38-39.

16. Aminabadi NA, Farahani RMZ, Balayi Gajan E (2008) The efficacy of distraction and counterstimulation in the reducing of pain reaction to intraoral injection by pediatric patients. J Contemp Dent Pract 9, 33-40.

17. Wright GZ, Weinberger SJ, Marti R, Plotzke O (1991) The effectiveness of infiltration anesthesia in the mandibular primary molar region. Pediatr Dent 13, 278-283.

18. Ram D, Peretz B (2003) The assessment of pain sensation during local anesthesia using a computerized local anesthesia (Wand) and a conventional syringe. J Dent Child 70, 130-133.

19. Ram D, Peretz B (2001) Reaction of children to maxillary infiltration and mandibular block injections. Pediatr Dent 23, 343-346.

20. Pashley EL, Nelson R, Pashley DH (1981) Pressures created by dental injections. J Dent Res 60, 17421748.

21. Allin KD, Kotil D, Larzelere RE, Hutfless S, Beiraghi S (2002) Comparison of a computerized anesthesia device with a traditional syringe in preschool children. Pediatr Dent 24, 315-320.

22. Peretz B, Efrat J (2000) Dental anxiety among young adolescent patients in Israel. Int J Pediatr Dent $10,126-132$.

23. Sharaf AA (1997) Evaluation of mandibular infiltration versus block anesthesia in pediatric dentistry. ASDC J Dent Child 64, 276-281.

24. Pinkham JR, Casamassimo PS, Fields HW, McTigue DJ, Nowak AJ (2005) Pediatric dentistry: infancy through adolescence. 4th ed, WB Saunders, Philadelphia, 130. 